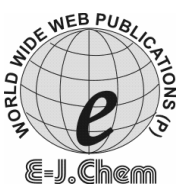

http://www.e-journals.net
ISSN: 0973-4945; CODEN ECJHAO

E-Journal of Chemistry

Vol. 5, No.3, pp. 572-576, July 2008

\title{
Plausible Applicability of Aqueous Congo Red Dye System as Secondary Gamma-ray Dosimeter
}

\author{
I. DAS SARMA* and D. V. PARWATE \\ Department of Chemistry, \\ Rashtrasant Tukadoji Maharaj Nagpur University, Nagpur - 440 033, India. \\ *dassarmaindrani@rediffmail.com
}

Received 18 November 2007; Accepted 10 January 2008

\begin{abstract}
Aqueous congo red dye solutions in the concentration range of $0.01-0.03 \mathrm{mM}$ were irradiated for varying $\gamma$ doses $0.050 \mathrm{kGy}$ to $0.150 \mathrm{kGy}$. The molar extinction coefficient of the dye solution of congo red was found to be $2.70 \times 10^{5}$ at its absorption maxima $499.0 \mathrm{~nm}$. No change in $\lambda_{\max }$ was observed on irradiation. As the dye solutions are sensitive towards $\gamma$-irradiation, decolouration occurs on irradiation. The G-values for the doses in between the range of $0.035 \mathrm{kGy}$ to $0.125 \mathrm{kGy}$ were found to be practically constant for pure aqueous systems. Hence this was used to determine the dose of the gamma source. With the addition of alcohols in the systems, degradation of the dyes due to radiations decreased considerably.
\end{abstract}

Keywords: Congo red, G-value, Radiolytic decomposition, Alcohols

\section{Introduction}

A system that measures the amount of energy absorbed from the ionizing radiation by virtue of the chemical changes produced in the system on exposure to the radiations is a chemical dosimeter ${ }^{1}$. The high energy radiations bring about the radiolysis of the dyes (decolouration or bleaching effect) which is used as a measure of the energy of the radiation incident on the system. The use of solutions of dyes such as methylene blue ${ }^{2}$, chlorantine fast green BLL $^{3}$ and coumarine ${ }^{4}$ for chemical dosimetry is reported. Congo red (C. I. No. 22120) or the di sodium salt of diphenyl diazo bis-1-naphthylaminesulphonic acid is brownish red powder having absorbance maxima at $499.0 \mathrm{~nm}$ in aqueous medium. The aqueous solution has $\mathrm{pH}$ 7.3 and the systems were stable for several hours. The decolouration of the dye as a result of $\gamma$-irradiation may be delayed using certain additives. In the present paper we have investigated the effect of alcohols in delaying the degradation of the dye. An attempt is made to explore the possible use of the aqueous congo red systems as high energy dosimeter. Ajji ${ }^{5}$ reported that alkaline methyl red dye solution could be used as chemical dosimeter for gamma rays in the range between 50 and 6000Gy. 


\section{Experimental}

Three concentrations of congo red dye solutions $(0.01,0.02$ and $0.03 \mathrm{mM})$ were studied with various concentrations of methanol $(0.31,0.62$ and $1.24 \mathrm{M})$, ethanol $(0.21,0.42$ and $0.86 \mathrm{M})$ and 1-propanol $(0.17,0.33$ and $0.67 \mathrm{M})$. All the solutions were prepared fresh using doubly distilled water and the $\mathrm{pH}$ of the systems were found to be 7.3. The absorbances of the irradiated solutions were recorded within ten minutes of irradiation, even though the stability of the solutions was quite higher (120 hours for unirradiated and 1.5 hours for irradiated solutions). Gamma irradiation was carried out in stoppered corning glass tubes having B24 standard joints in Cobalt-60 Gamma Chamber (GC 900) at a dose rate of $0.92 \mathrm{kGy} \mathrm{h}^{-1}$ $\left(5.741 \times 10^{18} \mathrm{eV} \mathrm{g}^{-1} \mathrm{~h}^{-1}\right)$. The dose rate was verified by Fricke dosimetry. Absorbed dose correction was carried out for calculation purpose using Z/A values for the system and Fricke dosimeter. The amount of dye decomposed was estimated by recording the absorbance at $499.0 \mathrm{~nm}$ on Shimadzu UV 240 spectrophotometer.

\section{Results and Discussion}

Pure aqueous congo red dye solution in the concentration range of $0.01-0.03 \mathrm{mM}$ were irradiated for varying $\gamma$ doses of $0.050-0.150 \mathrm{kGy}$. The decolouration due to irradiation with gamma rays showed a linear function up to $0.150 \mathrm{kGy}$ with respect to the absorbed dose in aqueous systems as can be seen in Figure 1.

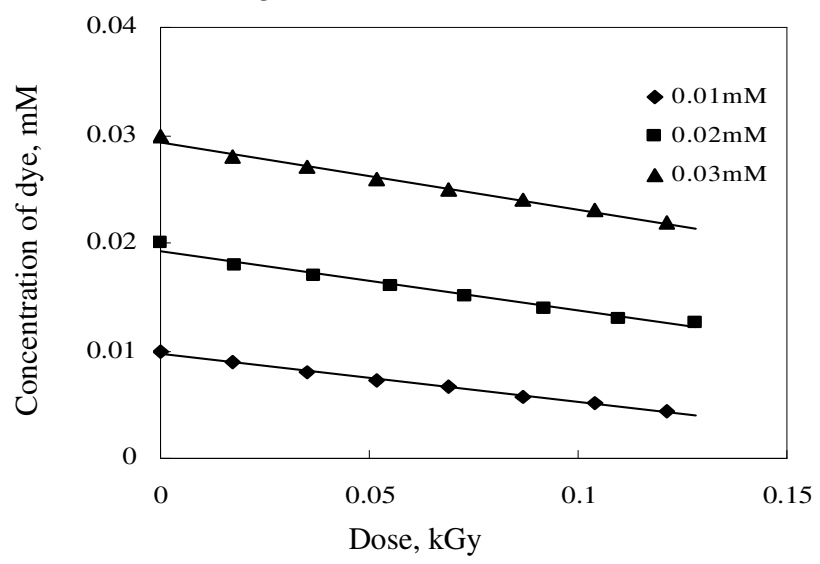

Figure 1. The graphs depicting radiolytic degradation of pure aqueous congo red dye solutions of $0.01,0.02$ and $0.03 \mathrm{mM}$.

It was expected that $\lambda_{\max }$ would get altered on $\gamma$-irradiation. However neither there was a change in $\lambda_{\max }(499.0 \mathrm{~nm})$ for the aqueous solution of the dye on $\gamma$-irradiation nor was it observed for aqueous solutions containing varying amounts of different alcohols. Our previous work ${ }^{6}$ suggests that $\mathrm{G}$-values for the congo red dye decomposed for doses in the range of $0.035 \mathrm{kGy}$ to $0.125 \mathrm{kGy}$ to be practically constant $57.69-68.26$ molecules (per $100 \mathrm{eV}$ ) for concentration range of $0.01-0.03 \mathrm{mM}$ in pure aqueous systems.

The dose required to bring the concentration of dye for $0.01 \mathrm{mM}$ system to $0.0071 \mathrm{mM}$ was found to increase from $0.050 \mathrm{kGy}$ in pure aqueous systems to $1000 \mathrm{~Gy}$ in aqueous alcoholic systems. Further from the graph as shown in Figure 2, it can be concluded that there is practically no decomposition of dye up to $0.750 \mathrm{kGy}$ of dose absorbed. Beyond this limit degradation is linear up to $1.750 \mathrm{kGy}$. The discoloration of the dye made it impossible to study the radiolytic degradation beyond $2.000 \mathrm{kGy}$. 
It is inferred from Figure 3 that the detection limit of gamma dose, $1.750 \mathrm{kGy}$ is not affected by increasing the concentration of the alcohols up to $5 \%$ (or 1.24, 0.86 and $0.64 \mathrm{M}$ for methanol, ethanol and 1-propanol respectively).

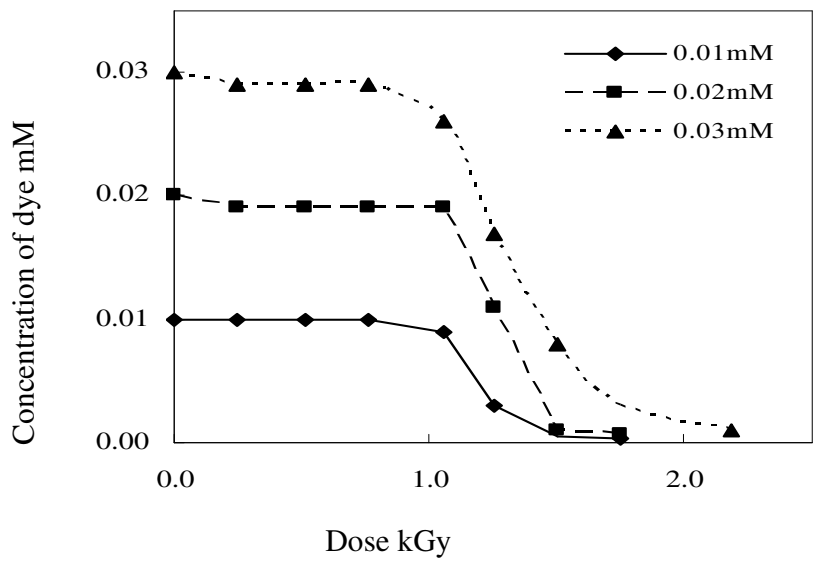

Figure 2. Radiolytic degradation of $0.01,0.02$ and $0.03 \mathrm{mM}$ congo red dye solutions in $5 \%$ aqueous methanol.

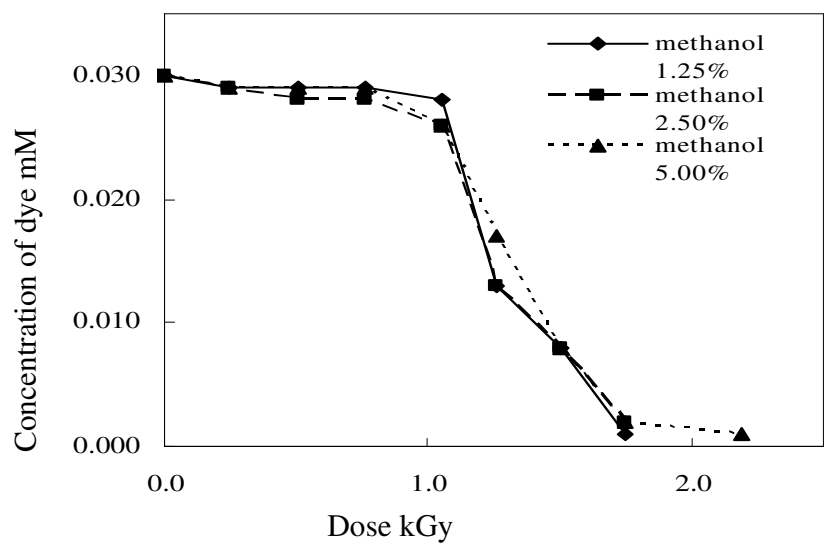

Figure 3. The graphs depicting radiolytic degradation of $0.03 \mathrm{mM}$ congo red dye solutions containing $1.25 \%, 2.5 \%$ and $5 \%$ methanol.

The Figure 4 depicts the trend for G (-dye) with dose rate. The graph initially declines upto $0.750 \mathrm{kGy}$ with increase in dose and thereafter it becomes more or less steady. This may be attributed to the presence of alcohols in the systems which retard degradation by interacting with the radicals that are generated in the systems. After a certain dose limit $(0.750 \mathrm{kGy})$ all the alcohols get used up there by accelerating the degradation of the dye with dose absorbed.

On $\gamma$-irradiation, aqueous systems are known to produce $\mathrm{e}_{\text {aq }}^{-}, \mathrm{H}^{\bullet}$ and $\mathrm{OH}^{*}$ as primary radicals. Also alcohols are well-known as $\mathrm{H}^{*}$ and $\mathrm{OH}^{*}$ radical scavengers. Methanol ${ }^{7}$ reacts with $\mathrm{H}^{*}$ and $\mathrm{OH}^{*}$ radicals either by abstracting a hydrogen atom from carbon or oxygen atom as shown in expressions (i) and (ii). 


$$
\begin{array}{ll}
\mathrm{H}^{\bullet}+\mathrm{CH}_{3} \mathrm{OH} \rightarrow \mathrm{H}_{2}+{ }^{\cdot} \mathrm{CH}_{2} \mathrm{OH} & \mathrm{k}=1.6 \times 10^{6} \mathrm{M}^{-1} \mathrm{~s}^{-1} \\
\mathrm{H}^{\bullet}+\mathrm{CH}_{3} \mathrm{OH} \rightarrow \mathrm{H}_{2}+\mathrm{CH}_{3} \mathrm{O}^{\bullet} & \\
\mathrm{OH}^{\cdot}+\mathrm{CH}_{3} \mathrm{OH} \rightarrow \mathrm{H}_{2} \mathrm{O}+\mathrm{CH}_{2} \mathrm{OH} & \mathrm{k}=8.4 \times 10^{8} \mathrm{M}^{-1} \mathrm{~s}^{-1} \\
\mathrm{OH}^{\bullet}+\mathrm{CH}_{3} \mathrm{OH} \rightarrow \mathrm{H}_{2} \mathrm{O}+\mathrm{CH}_{3} \mathrm{O}^{\bullet} &
\end{array}
$$

Since the rate constant is the same for abstraction of hydrogen attached either to carbon or oxygen atom in methanol molecule, both the reactions are equally possible.

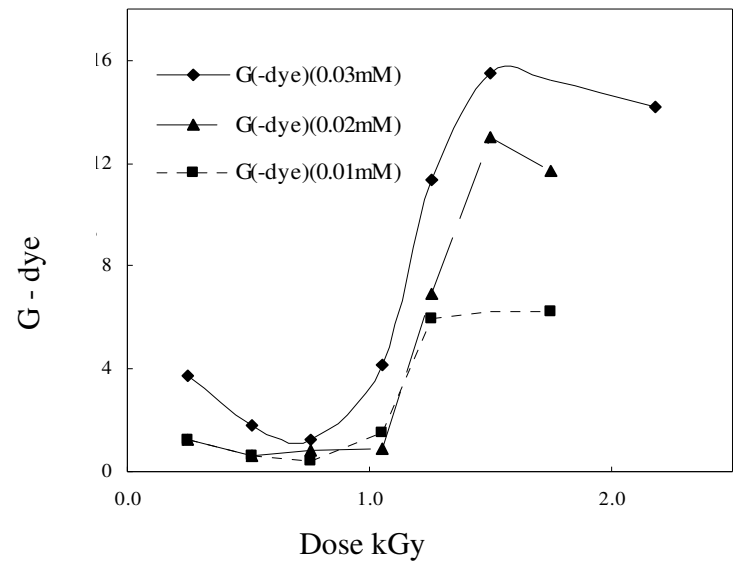

Figure 4.Trend for G-values in the accordance with the dose exposed in 5\% methanol system.

In air saturated systems interaction of $\mathrm{e}_{\mathrm{aq}}^{-}$at higher $\mathrm{pH}$ (7.3 in present systems) is low as they are readily scavenged by the dissolved $\mathrm{O}_{2}$. Nevertheless, probability of interaction of $\mathrm{e}_{\text {aq }}^{-}$with the water and alcohol in the system cannot be ignored. The reaction of $\mathrm{e}_{\text {aq }}^{-}$with water or alcohol in the systems is quite slow as is evident from the rate constants given in (iii) and (iv) respectively.

$$
\begin{array}{rr}
\mathrm{e}_{\mathrm{aq}}^{-}+\mathrm{H}_{2} \mathrm{O} \rightarrow \mathrm{H}+\mathrm{OH}^{-} & \mathrm{k}=16 \mathrm{M}^{-1} \mathrm{~s}^{-1} \\
\mathrm{e}_{\text {aq }}^{-}+\mathrm{CH}_{3} \mathrm{OH} \rightarrow \mathrm{H}+\mathrm{CH}_{3} \mathrm{O}^{-} & \mathrm{k}<10^{4} \mathrm{M}^{-1} \mathrm{~s}^{-1}
\end{array}
$$

At lower concentrations of methanol $\left(<10^{-2} \mathrm{M}\right)$ reaction of $\mathrm{e}_{\mathrm{aq}}^{-}$with water (iii) predominates rather than that with methanol (iv). This reaction (iv) is very slow and competes with (iii) and other reactions of $\mathrm{e}_{\text {aq }}^{-}$only at high concentrations of methanol (above $\left.10^{-2} \mathrm{M}\right)$. Since the concentration of the methanol (0.31, 0.62 and $1.24 \mathrm{M}$ respectively) in the systems studied are high enough, it is likely that the reaction with $\mathrm{e}_{\mathrm{aq}}^{-}$proceeds via reaction (iv) instead of (iii).

According to Spinks and Woods ${ }^{7}$ the radiolytic degradation of ethanol and 1-propanol are quite similar to that of methanol where $\mathrm{H}^{*}$ and $\mathrm{OH}^{\bullet}$ radicals react with the alcohol by abstracting $\mathrm{H}$ mainly from $\alpha$ carbon atom whilst the $\mathrm{e}_{\text {aq }}^{-}$in virtue of its less reactivity posses lesser chances of the dye degradation. The radicals formed by $\mathrm{H}$ abstraction rapidly add oxygen, forming peroxyl radicals in air saturated solutions which subsequently form hydrogen peroxide and carbonyl compounds. 
Thus the protection brought about by the addition of the alcohols can be attributed to the fact that the latter being scavengers react with the $\mathrm{H}^{*}$ and $\mathrm{OH}^{*}$ radicals generated due to the radiolysis of the water thereby reducing the chances of interaction of the dye molecule with the radicals. The data shows that alcoholic aqueous systems containing congo red dye can proposed as a secondary gamma ray dosimeter in the probable dose range of 500-1750Gy. Further studies using different $\gamma$ sources of various energies and dose rates are requisite to optimize the exact operating dose range of the dosimeter.

\section{Acknowledgements}

The authors thank the Head, Department of Chemistry, Rashtrasant Tukadoji Maharaj Nagpur University for providing the irradiation and laboratory facilities for the current work.

\section{References}

1. Gupta B L and Bhat R M, Handbook on calibration of high-dose radiation facilities (BARC), 1983, Chapter 1.

2. Vereshchinski I V and Pikaev A K, Introduction to Radiation Chemistry, Ed. Prof. G. Stein, Israel Program for Scientific Translations, Jerusalem, 1964, 272.

3. El-Assy N B, El-Wakeel E S and Abdel Fattah A, Int J Rad Appl Instrum [A]. 1991, $42,89$.

4. Collins A K, Makrigiorgos G M and Svensson G K, Med Phys. 1994, 21, 1741.

5. $\quad$ Ajji Z, Radiation Measurements. 2006, 41, 438.

6. Parwate D V, Das Sarma I and Batra R J, Radiation Measurements.2007, 42, 1527.

7. Spinks J W T and Woods R J, An Introduction to Radiation Chemistry, $2^{\text {nd }}$ Ed., Wiley Interscience Publications, New York, 1975, 317. 


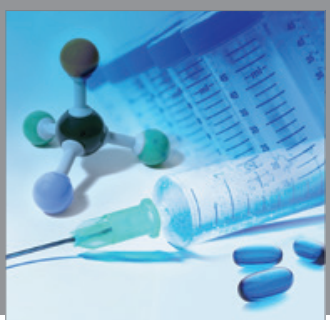

International Journal of

Medicinal Chemistry

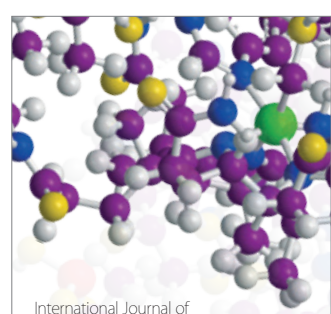

Carbohydrate Chemistry

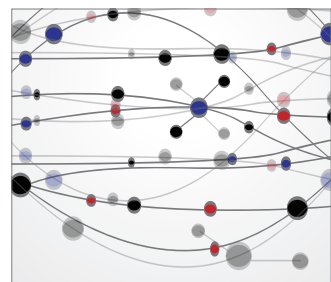

The Scientific World Journal
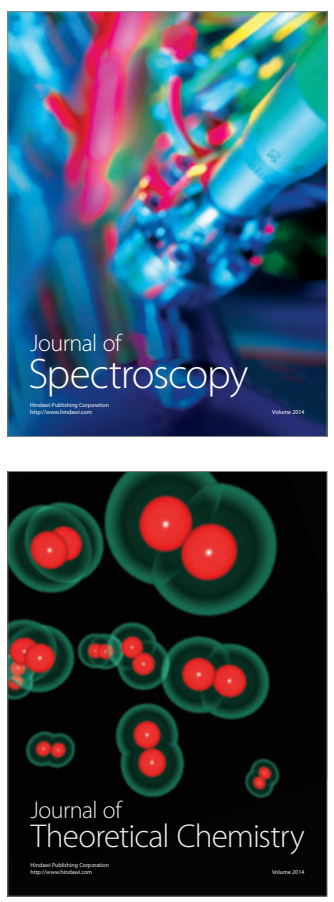
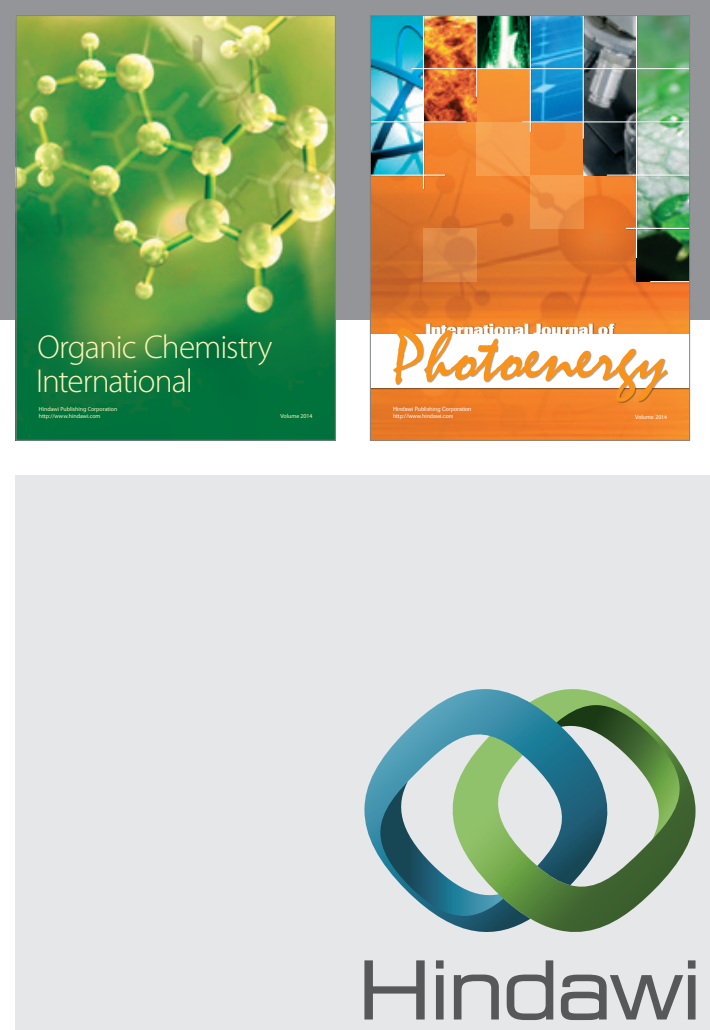

Submit your manuscripts at

http://www.hindawi.com
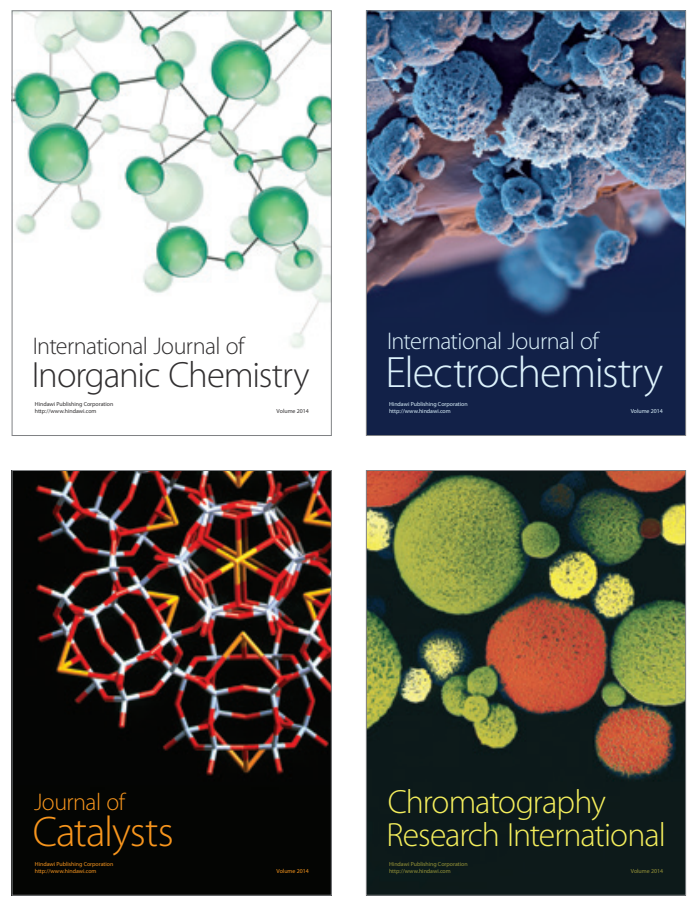
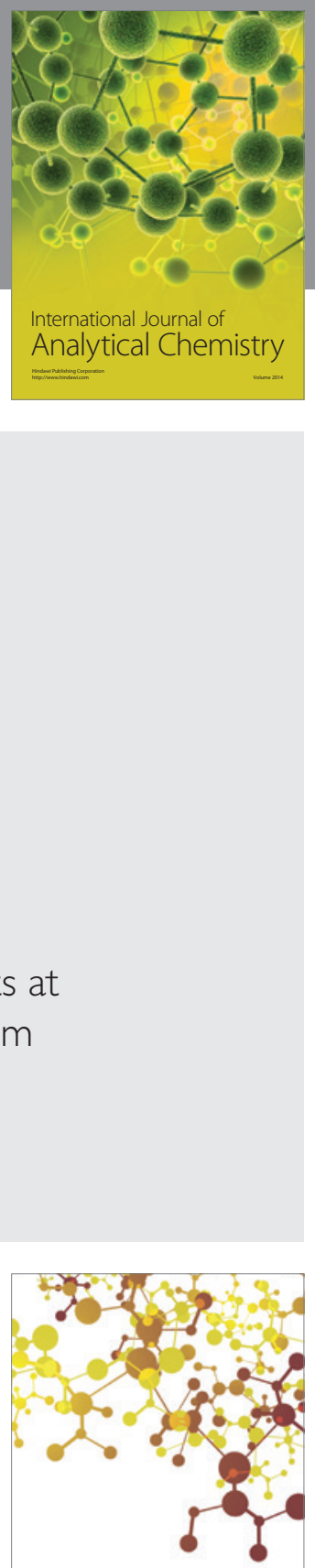

Journal of

Applied Chemistry
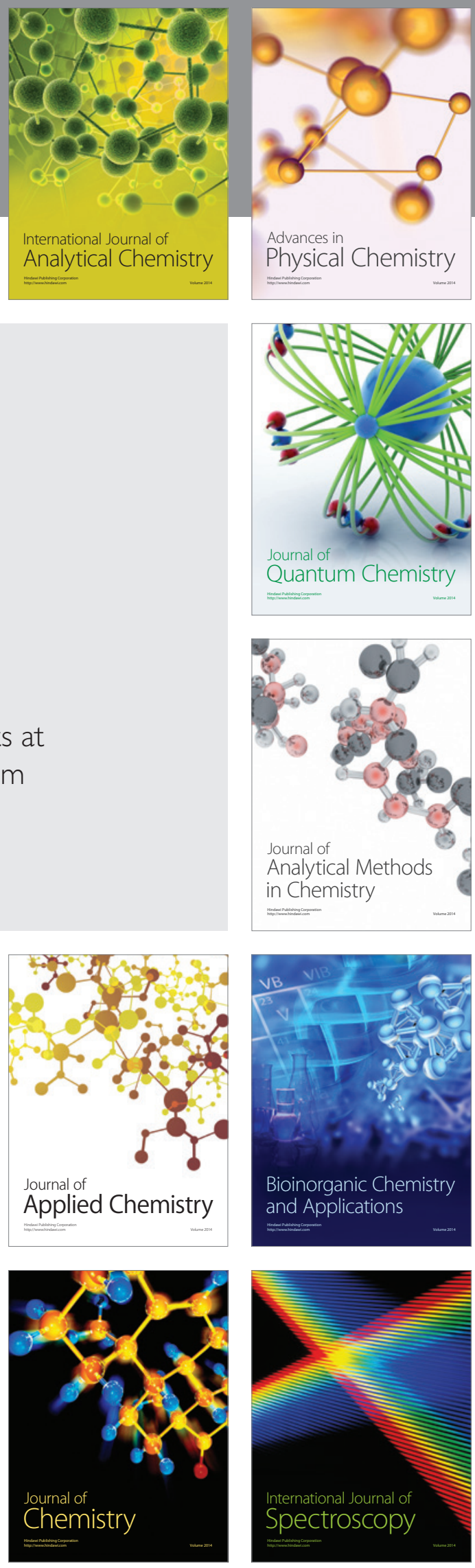